\title{
Plataforma A, colectivo vasco \\ PARA LA INCORPORACIÓN NORMALIZADA \\ DE LAS MUJERES EN EL SISTEMA DEL ARTE
}

Platform A, Basque Collective for the Normalized Incorporation

of Women into the Art System

\begin{abstract}
Txaro Arrazola
Artista visual, miembro de Plataforma A y profesora

de la Facultad de Bellas Artes de la Universidad del País Vasco.
\end{abstract}

\section{RESUMEN:}

Este texto aborda las actividades que realiza el colectivo Plataforma A por una visualización más equilibrada de artistas, comisarias y mediadoras en la institución arte. El colectivo pone en evidencia las convenciones de género en el marco de la representación que rige en la programación de exposiciones en el contexto del sistema del arte vasco. Asimismo, la plataforma recurre a la teoría feminista que revela la Historia del Arte como una disciplina legitimadora y perpetuadora de convenciones de género. Los análisis comparativos evidencian asimetrías claras tanto en la historia de los lenguajes artísticos que formulan una canonización masculina, como en el llamado gatekeeping del circuito expositivo principal, que implementa políticas que esencialmente consagran a artistas hombres, a pesar de que en la actualidad las mujeres tienen una mayor tasa de graduación en estudios artísticos superiores. Ante esta situación, la plataforma reclama que se vigile el cumplimiento de la legislación vigente para que empiece a producirse un verdadero cambio en la política cultural de las instituciones que garantice la visualización y la dignificación del trabajo de las artistas en el sistema del arte.

Palabras clave: acción colectiva, feminismo, arte, asimetrías, visualización, acción pública. 
RESUM: Aquest text aborda les activitats que realitza el col•lectiu Plataforma A per una visualització més equilibrada d'artistes, comissàries i mediadores en la institució art. El col•lectiu posa en evidència les convencions de gènere en el marc de la representació que regeix en la programació d'exposicions en el context del sistema de l'art basc. Així mateix, la plataforma recorre a la teoria feminista que revela la història de l'art com una disciplina legitimadora i perpetuadora de convencions de gènere. Les anàlisis comparatives evidencien asimetries clares tant en la història dels llenguatges artístics que formulen una canonització masculina, com en l'anomenat gatekeeping del circuit expositiu principal, el qual implementa polítiques que essencialment consagren artistes homes, malgrat que en l'actualitat les dones tenen una major taxa de graduació en estudis artístics superiors. Davant aquesta situació, la plataforma reclama que es vigile el compliment de la legislació vigent perquè comence a produir-se un vertader canvi en la política cultural de les institucions que garantisca la visualització i la dignificació del treball de les artistes en el sistema de l'art.

Paraules clau: acció col·lectiva, feminisme, art, asimetries, visualització, acció pública.

ABSTRACT: This article describes the activities of the Plataforma A collective for more equal visibility of women artists, curators and intermediaries in the art institution. The collective highlights the gender conventions in the predominant framework of representation in exhibition programming in the context of the Basque art system. At the same time the platform draws on feminist theory showing art history as a discipline that legitimises and perpetuates gender conventions. Comparative analyses demonstrate clear asymmetries both in the history of artistic languages that shape masculine canonisation, and in the gate-keeping practices on the main exhibition circuit, which implements policies that essentially sanctify male artists even though today more women graduate from higher education in art than men. In response to this situation, the platform calls for the monitoring of legislative enforcement in order to bring about a real change in institutions' cultural policies that will guarantee the visualisation and dignity of women's work in the art system.

KEYWORDs: collective action, feminism, art, asymmetries, visualization, public action. 


\section{Definición de la Plataforma y el contexto}

$\mathrm{P}$ lataforma $\mathrm{A}$ es un colectivo de profesionales del sector del arte y la cultura que nace en el País Vasco en 2011 ante la necesidad de realizar acciones y estrategias que reivindiquen la igualdad de derechos de las mujeres, amparadas por las leyes de igualdad ${ }^{1}$ frente a la sistemática discriminación sexista e invisibilización de la que son objeto en los museos, centros culturales y en general en el sistema del arte. Hemos realizado un seguimiento de los museos de arte moderno y contemporáneo en la Comunidad Autónoma Vasca en los últimos años, si bien el sesgo androcéntrico del campo artístico se da también a nivel nacional e internacional.

El movimiento social y teórico feminista que comienza a desplegarse desde el siglo XVIII nos proporciona una genealogía en la que encuadrar nuestro trabajo. En el siglo xx, desde finales de los años sesenta, en las sociedades occidentales se producen una serie de movilizaciones de grupos feministas al hilo de las teorías planteadas por Simone de Beauvoir en El segundo sexo (1949) que revelan el género como una construcción social. Estas movilizaciones propician la aparición de nuevas prácticas artísticas y nuevos análisis filosóficos que crean un marco teórico para impulsar un cambio de perspectiva en torno a la igualdad en el campo del arte: «descubrir que la tríada sexo/ género/sexualidad se construye socioculturalmente y que el correlato hegemónico-normativo que impera en nuestras sociedades, además de ser arbitrario, tiene una historia específica» (Arakistain, 2014), necesariamente nos aporta herramientas para trabajar con una nueva perspectiva.

A finales de los años sesenta teóricas como Nochlin² o Lippard ${ }^{3}$ reflexionan sobre el significado de los conceptos artista y genio y empiezan a cuestionar por qué no se ha considerado a las artistas merecedoras de dicho nivel

1. En 2005 el Parlamento vasco aprobó la Ley para la Igualdad de Mujeres y Hombres. En 2007 el Parlamento español aprobó la Ley para la Igualdad Efectiva de Mujeres y Hombres.

2. Nochlin, Linda (1973 [1971]): «Why have there been no great women artist?», en Hess, Th. B. ; E. C. Baker (eds.) Art and sexual politics, Nueva York, Macmillan, 1-43. En este artículo ya legendario del año 1971 que sigue siendo de plena actualidad, Linda Nochlin se preguntaba por qué no ha habido grandes mujeres artistas y cuál es la razón de que el genio artístico haya sido visibilizado a lo largo de la historia como privativo del género masculino.

3. Lippard, Lucy R. (1976): From the Center. Feminist essays on women's art, Toronto, Fitzhenry \& Whiteside Limited. 
jerárquico, rango e importancia en el campo artístico y en la historia del arte. A su vez, en los ochenta el colectivo Guerrilla Girls ${ }^{4}$ comienza a denunciar por medio de su obra el sexismo y racismo imperantes en el sistema del arte. Las Guerrilla Girls nos siguen recordando en pleno siglo XxI que las mujeres artistas siguen cotizando a la baja y nos siguen emplazando en ese lugar que nos proporciona la política feminista y que nos invita al hacer y al placer de nombrar a las cosas por su nombre (Vila Núñez, 2007). En definitiva, el feminismo engloba a un tiempo un conjunto de ideas y un movimiento de cambio social y político fundado sobre el rechazo de los privilegios masculinos y de la subordinación de las mujeres en el seno de una determinada sociedad (Offen, 2012).

Plataforma A comienza su andadura en esta tradición consciente de que el movimiento feminista es un aspecto especialmente conflictivo de la historia de Occidente incluso entre las mujeres, es olvidado o condenado y, sin embargo, hay constantes esfuerzos por revitalizar su legado porque el conocimiento y la experiencia nos remiten a que desde esta tradición cultural y política se pueden generar realidades más completas y visibles para todos/as (Vila Núñez, 2007).

Plataforma A se alinea con las prácticas artísticas y activistas feministas que trabajan para visibilizar e incluir a las mujeres en la historia de la humanidad y escribir una verdadera historia de historias (Pollock, 1994, 2008) que no dejen al margen a más del cincuenta por ciento de la población. Griselda Pollock utiliza la forma plural «historias del arte» porque no cree en la existencia de una narrativa única o un marco unificado para comprender las numerosas historias del arte que aún quedan por escribir, por eso afirma que «no puede haber un relato incuestionable del pasado, porque lo que se canoniza asegura activamente la discriminación y las jerarquías del presente. La forma en que construimos el pasado predetermina las formas en que experimentamos el presente e imaginamos el futuro. Por ello la escritura de las historias del arte es un asunto profundamente político en cuanto a nuestra percepción

4. Las Guerrilla Girls además de denunciar en tono humorístico el androcentrismo del sistema del arte, se caracterizan porque lo hacen aportando porcentajes que evidencian la ausencia de reconocimiento para las artistas en los grandes museos de Nueva York y otras ciudades estadounidenses, así como en el mundo del cine. Esta práctica ha sido rigurosamente adoptada tanto por la Plataforma A, como por la asociación MAV y por otros colectivos, el objetivo es poner de relieve el desfase de la visibilidad de la creación femenina con números, demostrando que ese desfase no es sólo ideológico sino cuantificable. 
de lo que somos, hemos sido o podríamos ser» (Pollock, 2008). Los museos construyen historia y la crean. El problema no sólo está en que a las artistas se les destierre o se les desarraigue, sino que nunca han ocupado ese espacio de un modo socialmente reconocido (Méndez, 1987), quizá porque lo femenino en tanto que género se sigue viendo al margen de lo universal y de lo neutro-masculino, es decir, que lo genéricamente humano sigue asociándose exclusivamente con lo masculino (Amorós, 1985).

En pleno siglo XXI el citado sesgo androcéntrico del arte, lejos de haber sido erradicado, continúa imperando tanto en el mercado del arte como en los circuitos museísticos y expositivos, excepto en contados y excepcionales casos donde se han desarrollado programas aplicando sistemas de cuotas, como es el caso del Centro Cultural Montehermoso Kulturunea de Vitoria bajo la dirección de Xabier Arakistain (2007-2011) o el Moderna Museet de Estocolmo y su política adquisitiva paritaria para compensar los fondos de su colección permanente.

Representación de artistas por sexos en las exposiciones individuales realizadas de 2000 a 2015 en 3 los museos más visitados de la Comunidad Autónoma Vasca

\begin{tabular}{|c|c|c|c|c|c|c|c|c|c|c|}
\hline & \multicolumn{4}{|c|}{ SUB-REPRESENTACIÓN } & \multicolumn{2}{|c|}{$\begin{array}{l}\text { PARIDAD } \\
\text { (presencia } \\
\text { equilibrada) }\end{array}$} & \multicolumn{4}{|c|}{ SOBRE-REPRESENTACIÓN } \\
\hline & $\stackrel{\stackrel{0}{0}}{\stackrel{1}{1}}$ & $\frac{\dot{0}}{\dot{\theta}}$ & 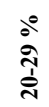 & $\begin{array}{l}\stackrel{\circ}{0} \\
\text { हे }\end{array}$ & $\begin{array}{l}\stackrel{0}{ } \\
\grave{j} \\
\dot{\sigma}\end{array}$ & i̊ & 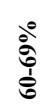 & $\begin{array}{l}\stackrel{\circ}{\hat{i}} \\
\stackrel{2}{\hat{n}}\end{array}$ & $\begin{array}{l}\stackrel{0}{0} \\
\stackrel{\alpha}{0} \\
\vdots\end{array}$ & $\begin{array}{l}0 \\
a \\
+ \\
+\end{array}$ \\
\hline 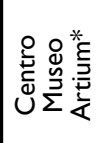 & & $\begin{array}{l}\text { Exposi- } \\
\text { ciones de } \\
\text { artista mujer } \\
16 \%\end{array}$ & & & & & & & $\begin{array}{l}\text { Exposiciones } \\
\text { de artista } \\
\text { hombre } \\
84 \%\end{array}$ & \\
\hline 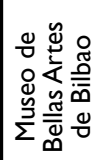 & $\begin{array}{l}\text { Exposi- } \\
\text { ciones de } \\
\text { artista mujer } \\
0 \%\end{array}$ & & & & & & & & & $\begin{array}{l}\text { Exposiciones } \\
\text { de artista } \\
\text { hombre } 100 \%\end{array}$ \\
\hline 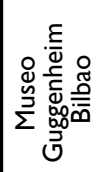 & & $\begin{array}{l}\text { Exposi- } \\
\text { ciones de } \\
\text { artista mujer } \\
11,67 \%\end{array}$ & & & & & & & $\begin{array}{l}\text { Exposiciones } \\
\text { de artista } \\
\text { hombre } \\
88,33 \%\end{array}$ & \\
\hline
\end{tabular}

*Los datos de Artium son desde 2002, año de su apertura al público. La recolección de datos se llevó a cabo a través de la compilación de exposiciones publicadas en las páginas webs de los propios museos Fuente: Plataforma A.

Tabla 1. Representación de artistas mujeres y hombres en las exposiciones individuales realizadas de 2000 a 2015 en 3 los museos más visitados de la Comunidad Autónoma Vasca. 
Esta tabla refleja que en los museos y centros de arte vascos las artistas están infrarrepresentadas en las exposiciones individuales. Se trata de una discriminación por razón de sexo que impide a las artistas alcanzar estatus profesionales reservados mayoritariamente para el género masculino. Una realidad que se ve reafirmada por el sesgo androcéntrico de las colecciones de los museos y que es especialmente grave en el caso de la colección del Museo de Bellas Artes de Bilbao, donde hay una ausencia casi total de obras y discursos de grandes artistas mujeres, las cuales son completamente ignoradas.

Si consideramos que el Arte es la expresión y la creación propia de individuos inmersos en un contexto cultural (Méndez, 1987), el individuo artista es una realidad social, cultural $y$, en este sentido, es fundamental incorporar a las artistas y sus discursos diferenciados en el sistema del arte para lograr colecciones abiertas a la diversidad

Sin embargo, en el citado Museo de Bellas Artes de Bilbao, de las 44 exposiciones individuales programadas entre 2002 y 2013 ni una sola de ellas fue dedicada a una artista (Barcenilla, 2011). En el año 2014 el museo recibió la donación por parte de la pintora Marta Cárdenas (San Sebastián, 1944) de un conjunto relevante de obras suyas, que comprendía 295 obras sobre papel y 55 cuadernos de artista, y tras la donación el museo programó ese mismo año una exposición con una selección de dichas obras. Era la primera exposición de una artista mujer desde el año 1986 en que el museo había realizado otra dedicada a M. Puri Herrero, es decir, habían pasado 28 años sin programar una sola exposición de una artista.

Así mismo, en un museo de arte contemporáneo como el Guggenheim, sorprende comprobar que han pasado10 largos años sin dedicar una sola exposición a una artista. De 2003 a 2013 el 100\% de las exposiciones individuales en el museo Guggenheim Bilbao fueron monográficas de artistas hombres. Actualmente parece haberse mejorado ligeramente esa tendencia con la programación de una exposición individual de Yoko Ono en 2014 y otra de Niki de Saint Phalle en 2015.

Estas cifras en los museos contrastan fuertemente con la cantidad de mujeres formadas en arte. Para las artistas, mediadoras, historiadoras y comisarias que integramos la plataforma es preocupante ver cómo muchas profesionales con una sólida formación no llegan a los espacios de legitimación porque los mundos de la decisión y del liderazgo continúan siendo masculinos. El ejem- 
plo más cercano lo tenemos en la facultad de Bellas Artes de la Universidad del País Vasco donde del total de alumnado matriculado entre 2000 y 2015, el $28,5 \%$ fueron varones y el 71,5 \% mujeres. Los artistas son minoría en la universidad y, en cambio, están sobrerrepresentados en los museos, mientras que las artistas son amplia mayoría en la universidad y están infrarrepresentadas en los museos.

Tratándose de museos de arte contemporáneo donde gran parte de las exposiciones individuales programadas son de artistas vivos, nos preguntamos por qué sigue ocurriendo esto y qué consecuencias tiene esta realidad. Mujeres y hombres aprendemos a ser según cómo la sociedad nos valora. Por eso, seleccionar qué artistas se exponen en un determinado museo o centro de arte es una cuestión crucial porque a través de cada elección se está creando un discurso que visualiza y perpetúa un modelo concreto de artista e ignora otros.

En el resto del Estado nos encontramos con cifras similares durante la primera década del siglo xxi. Sobre exposiciones individuales en 22 centros de arte contemporáneo en España desde 1999 a 2009, el porcentaje de exposiciones individuales de artistas españolas es 9'4\%, (Informe MAV 5, 2011). ${ }^{5}$ Sobre 10 museos de arte contemporáneo observados en el Estado, la presencia de artistas mujeres en sus colecciones es el 13\%, y de obras de artistas españolas, el 10’4\%, (Informe MAV 7, 2011).

La Plataforma A se pregunta y pregunta a las instituciones dónde están las exposiciones consagradas a mujeres que han contribuido igualmente a la historia del arte nacional e internacional.

Esta cuestión nos sitúa ante la necesidad de cambiar el imaginario colectivo para que las obras creadas por las artistas sean legitimadas como referentes por los distintos centros y museos que componen el circuito expositivo local e internacional, y puedan ser reconocidas por el público en general, así como por la crítica y por los demás artistas pares y en formación. Si el 70\% del alumnado de la facultad de BBAA son alumnas, para que haya un cambio y una emancipación en ellas, es necesario que puedan fijarse en artistas mujeres cuando necesiten modelos de referencia diversos, unos modelos difíciles de encontrar en un contexto artístico vasco de por sí dominado por una tradición repleta de escultores.

5. www.mav.org (accedido el 18 de abril de 2016) 


\section{Actividad de la Plataforma}

La Plataforma A funciona por medio de asambleas abiertas a toda persona interesada en la construcción colectiva de la historia, desde un punto de vista feminista y de género. La plataforma inicia su andadura con la colaboración de una serie de personas y asociaciones que trabajan por la igualdad en la cultura, así como un amplio sector de profesionales del arte, de hecho uno de los objetivos de la plataforma es reunir a los distintos grupos y personas que ya están trabajando por la igualdad de forma independiente para sumar esfuerzos que ayuden a dar pasos eficaces hacia una mejora de la situación. La plataforma trabaja desde un sitio $\mathrm{web}^{6} \mathrm{y}$ desde el grupo «A Plataforma» en la red social Facebook. ${ }^{7}$

La pionera Ley 4/2005 en su artículo 25 punto 1 especifica que «las administraciones públicas vascas, en el ámbito de sus competencias, han de adoptar las medidas necesarias para evitar cualquier discriminación por razón de sexo y para promover un acceso y participación equilibrada de mujeres y hombres en todas las actividades culturales que se desarrollen en el ámbito de la Comunidad Autónoma de Euskadi». ${ }^{8}$

Desafortunadamente, como hemos comprobado, los informes demuestran que todavía queda mucho camino por recorrer para lograr una participación mínimamente simétrica de las profesionales del arte. Con este objetivo Plataforma A, siempre por medio de asambleas, ${ }^{9}$ adopta dos líneas de trabajo:

- Acciones institucionales.

- Acciones simbólicas o performances en el espacio público.

6. www.wiki-historias.org (accedido el 18 de abril de 2016).

7. https://www.facebook.com/groups/aplataforma/ (accedido el 18 de abril de 2016).

8. Ley $4 / 2005$, de 18 de febrero, para la Igualdad de Mujeres y Hombres. Gobierno Vasco.

9. Hasta el momento se han realizado 14 asambleas, denominadas «topaketak»o «encuentros», en distintos espacios culturales del País Vasco; el 14 encuentro tuvo lugar en Bilbao el 23 de marzo de 2016. 


\section{Acciones institucionales}

Estas acciones han consistido en solicitar entrevistas cara a cara con las personas responsables de las administraciones públicas de la comunidad autónoma vasca (ver fig.1). En las entrevistas, la Plataforma A les demanda una respuesta firme ante la situación de profunda desigualdad que seguimos viviendo en pleno siglo XXI.

La primera acción fue la redacción de una carta dirigida al lehendakari, ${ }^{10}$ un documento donde se denunciaba el incumplimiento de las leyes de igualdad vigentes y se instaba a tomar medias. Si bien el lehendakari nunca recibió a la comisión de la Plataforma A en persona, el solo intento de contactar con él derivó en otras entrevistas con los siguientes políticos y políticas de las distintas consejerías del gobierno vasco: la Consejera de Cultura Blanca Urgell (21/09/2012), la Consejera de Educación Isabel Celaá (27/11/2012), el Ararteko (defensor del pueblo vasco) Iñigo Lamarka (13/09/2013), Izaskun Landaida como presidenta de Emakunde/Instituto vasco de la mujer (02/10/2013) $\mathrm{y}$, tras las elecciones autonómicas, la plataforma se entrevistó en dos ocasiones con el nuevo Viceconsejero de Cultura, Josean Muñoz (29/01/2014 y 30/10/2014).

En todas las entrevistas Plataforma A pone sobre la mesa los informes que analizan la representación de artistas mujeres y hombres en los museos de la Comunidad Autónoma Vasca y cuestiona a la institución pública, en primer lugar, qué está haciendo para corregir la situación de desigualdad y violencia simbólica y, en segundo, por qué se está permitiendo que se incumpla la ley incluso en los centros de arte financiados con presupuestos públicos.

Todas y cada una de las personas entrevistadas se mostraron sorprendidas por la asimetría de los porcentajes, lo que indica que se trata de una discriminación que ni siquiera vemos quizá porque estamos ante una política oficial basada en la proclamación de la igualdad entre todos los hombres pero en la práctica existen sectores sociales maltratados o discriminados por su condición sexual. Resulta sorprendente que las mismas instituciones no realicen

10. En su cuarto encuentro, la plataforma organizó una recogida de firmas online donde se puede leer la carta dirigida al lehendakari: http://www.change.org/es/peticiones/a-toda-la-sociedad-denunciar-la-desigual-

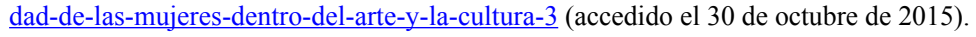


sus propios estudios para comprobar si se están dando pasos hacia el cumplimiento progresivo de la ley. Es evidente que si no somos conscientes de una realidad, no podemos ajustar nuestras políticas en una dirección de mejora.

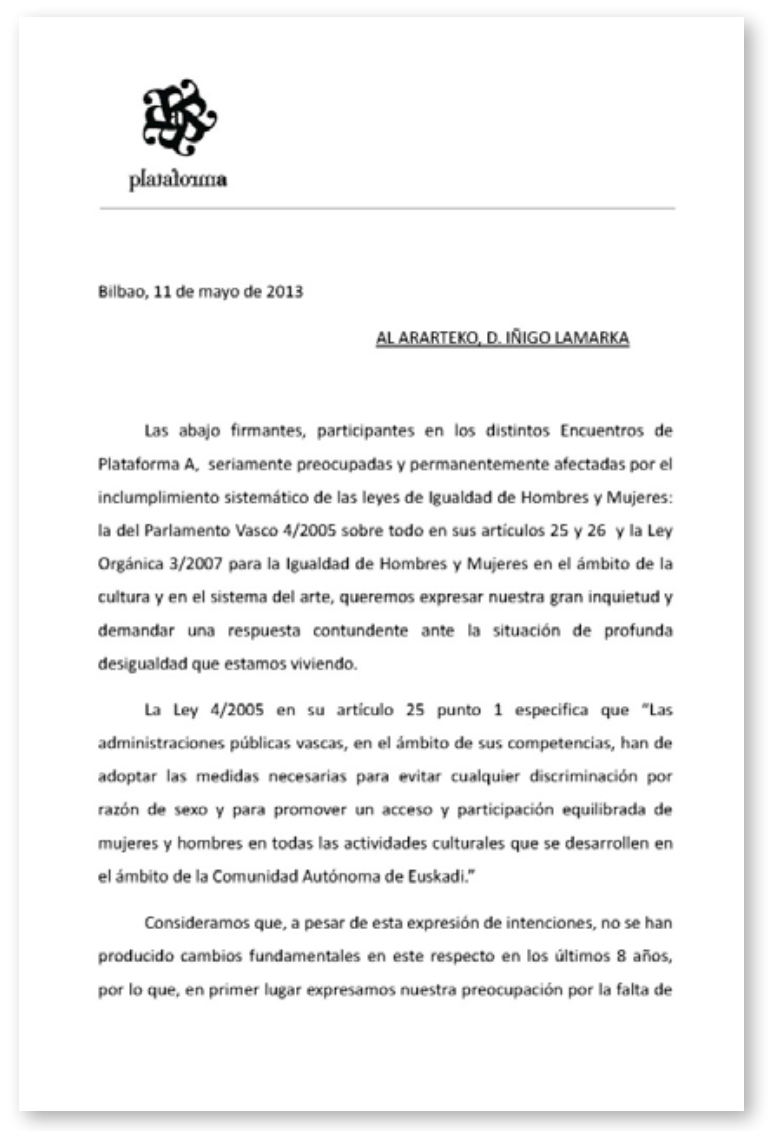

Figura 1. Fragmento de la carta dirigida al Ararteko con fecha 11/5/2013 previa a la entrevista en persona.

La plataforma reivindica la necesidad de hacer cumplir las leyes a los centros e instituciones con participación pública, es decir, que los museos y centros de arte vascos presenten y aprueben programas de igualdad en los que se refleje la aplicación de la ley 4/2005. Creemos que es necesario que tanto la sociedad como los responsables políticos sean conscientes de que existe una Ley de Igualdad y que su cumplimiento debe ser exigido por las instituciones competentes. Así mismo, que se pregunten cuáles son las razones por las que se incumple y cuál es la educación social al respecto, puesto que no hacerlo parece asumir que la desigualdad es algo natural y eso hace que sigan 
mirando para otro lado ante el incumplimiento de las medidas existentes para erradicarla. La discriminación sistemática hace que las mujeres seamos menos valoradas en función del género y no por la calidad del trabajo o de nuestras aportaciones creativas e intelectuales a la sociedad. Lo cual conlleva invisibilidad, un menor reconocimiento, difusión y retribución por el trabajo realizado.

Recordemos que el punto 2 del artículo 25 de la citada ley vasca 4/2005 dice que «las administraciones públicas vascas no podrán conceder ningún tipo de ayuda ni sus representantes podrán participar en calidad de tales en ninguna actividad cultural, incluidas las festivas, las artísticas, las deportivas y las realizadas en el ámbito de la normalización lingüística del euskera, que sea discriminatoria por razón de sexo». Por ello la plataforma exige el cumplimiento con carácter de urgencia de esta ley y, si es necesario, que se sancione a los centros que no la cumplen con la supresión de apoyos públicos, que entendemos como paso indispensable en el reconocimiento de la situación de injusticia a la que se enfrentan las mujeres en el ámbito del arte contemporáneo.

La plataforma insta a las instituciones que gobiernan para que incidan fundamentalmente en los siguientes aspectos: órganos de gobierno, presupuestos, educación, visibilización, programación y adquisición de obra.

- A los órganos de gobierno se les pide el cumplimiento de la legalidad aplicando criterios de igualdad y paridad a la hora de constituir la composición de los correspondientes órganos de gobierno en centros e instituciones de arte y cultura, así como en jurados y comités de decisión.

- En cuanto a los presupuestos, la plataforma demanda un reparto igualitario de los presupuestos para actividades de formación de profesionales y aplicar criterios de igualdad en la elaboración de los presupuestos de compra de obras de arte y patrimonio con recursos públicos.

- En el campo de la educación, incluir un pensamiento democrático e igualitario, que incorpore la igualdad como factor transversal en las programaciones y currículos académicos de los centros educativos de la Comunidad Autónoma Vasca. 
- En cuanto a la visualización, la Plataforma A trabaja por una difusión seria y profesional del tema de la igualdad en prensa, radio, televisión, internet, etc. Así mismo, para que las mujeres en los sectores directivos de la Cultura asuman estos objetivos y los reclamen en todos aquellos lugares que puedan acceder.

- La programación expositiva, como se ha visto anteriormente, es una de las reivindicaciones más importantes de este colectivo. En las reuniones con responsables institucionales, solicita que todas las programaciones participadas con fondos públicos observen el porcentaje de artistas hombres y mujeres en las exposiciones individuales y colectivas, así como el número de comisarios y comisarias, ponentes, etc. de manera que sean efectivamente cumplidas las leyes en su totalidad con respecto a la presencia equilibrada de mujeres y hombres.

- En el terreno de la adquisición de obra para las colecciones, demandamos el fomento y la ordenación del patrimonio artístico contemporáneo en términos paritarios. Así mismo, la recuperación y creación de archivos de artistas mujeres desde la modernidad que redunden en un incremento patrimonial de obras de artistas mujeres en las colecciones, los museos y los equipamientos culturales públicos.

\section{Acciones simbólicas}

Las performances en el espacio público tienen como objetivo lograr un poco más de justicia en el sistema de representación, la educación y formación de públicos. Además de lograr una conexión directa con la ciudadanía, conforman también una forma de presión hacia las administraciones públicas sabedoras del impacto social que tienen estas acciones en la calle. Dos de las acciones públicas han tenido lugar frente a los museos observados y se han hecho coincidir con el día internacional de los museos, la tercera acción se realizó en la entrada de acceso a la facultad de Bellas Artes haciéndola coincidir con el décimo aniversario de la Ley Vasca de Igualdad del 18 de febrero de 2005. Estas tres acciones son:

- «ASALTA»

- «BRINDIS»

- «TÚ NO» 


\section{Acción «ASALTA»}

Acción realizada frente a los museos de Bilbao el 18/05/2013, coincidiendo con el día internacional de los museos, que consistió en recorrer los alrededores del Museo de Bellas Artes de Bilbao, el museo Guggenheim y la Plaza Circular Don Diego López de Haro; veinticinco integrantes de la plataforma, ataviadas con pantys en la cabeza y banderolas con el emblema de la Plataforma A, declamaron consignas y saltaron simbólicamente las esculturas públicas de los alrededores de esos espacios.

Esta acción fue muy importante para la plataforma porque supuso un paso en el reconocimiento del poder del colectivo, que se hizo consciente de su fuerza. Por una parte vimos cómo los responsables de los museos se ponían nerviosos y, por otra, tuvimos la certeza de estar actuando en nombre de todas las artistas ignoradas y olvidadas en los sótanos de los museos. Además tuvimos la suerte de recibir bastante atención de los medios de comunicación por lo que la acción tuvo un alcance más allá de la mera performance del día internacional de los museos.

Para la acción realizamos una plantilla de gran tamaño con el logotipo de la plataforma que pintamos en las banderas (fig. 2), así como 7 modelos diferentes de pegatinas que utilizamos en distintos centros culturales y museos que adolecen de una notoria asimetría en la incorporación de artistas mujeres.

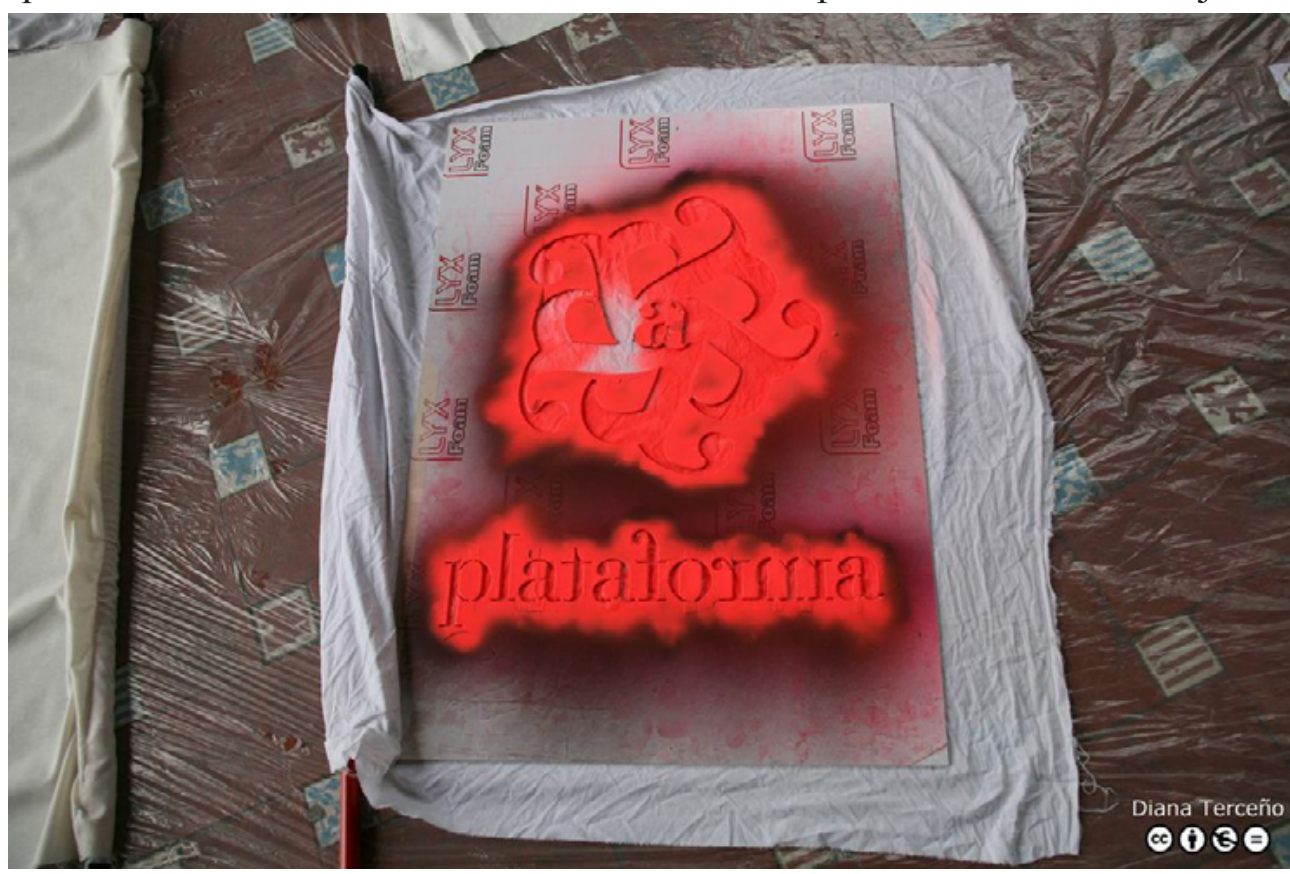

Figura 2. Plantilla para las banderas utilizadas en la acción «ASALTA», Bilbao 18 de mayo de 2013. Fotografía: Diana Terceño. 


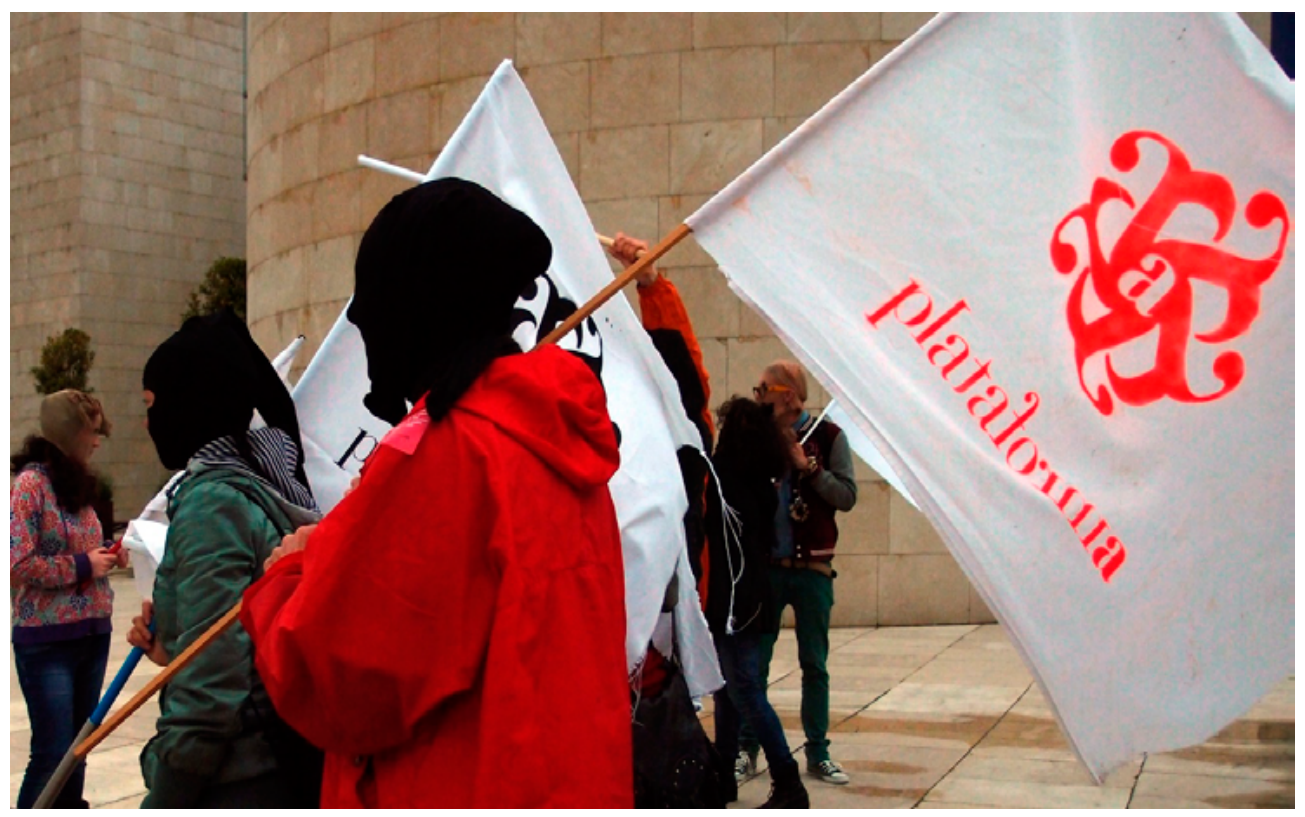

Figura 3. Acción «ASALTA», Bilbao 18 de mayo de 2013. Fotografía: Chus Gutiérrez-Solana.

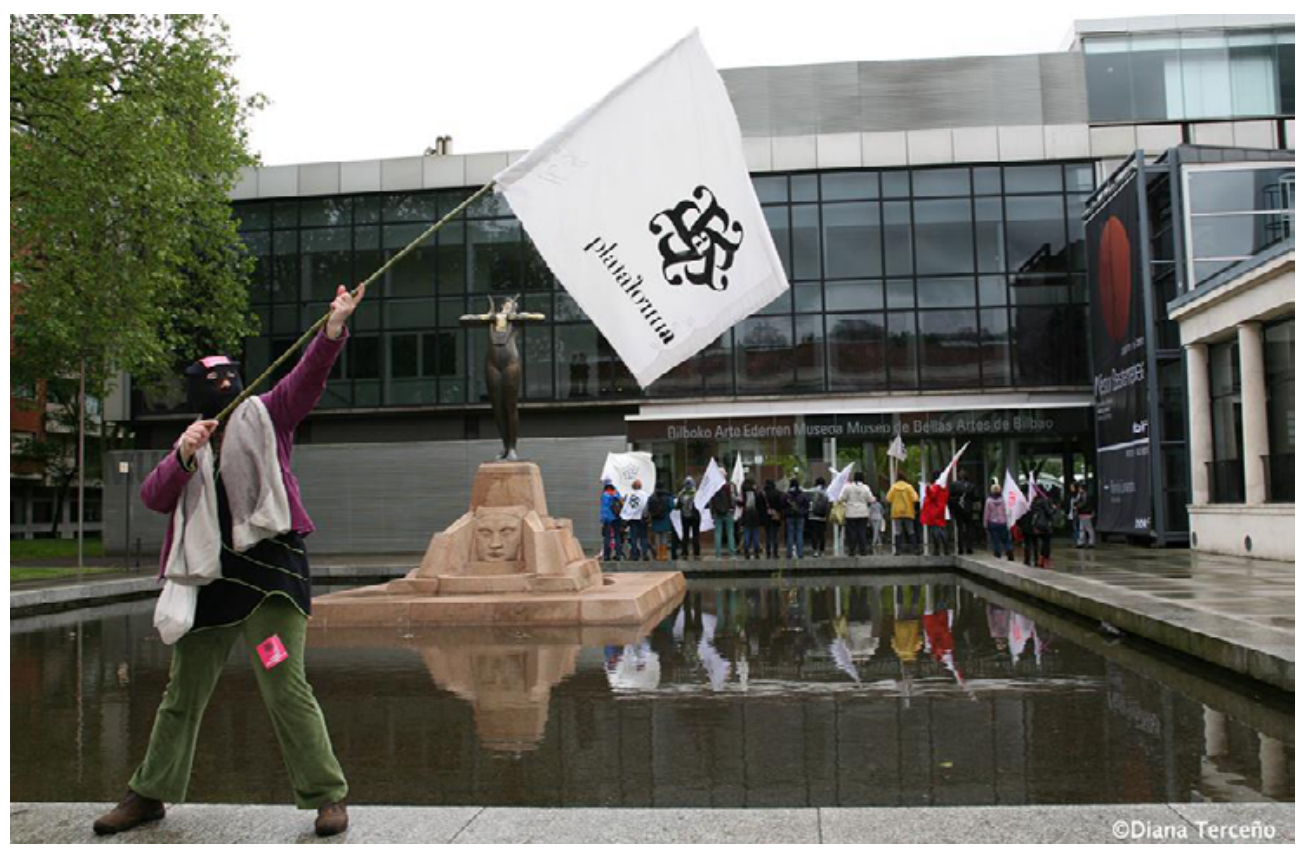

Figura 4. Acción «ASALTA», Bilbao, 18 de mayo de 2013.

Fotografía: Diana Terceño. 


\section{Acción «BRINDIS»}

La acción fue realizada frente a los museos de Vitoria-Gasteiz el 17/05/2014, día internacional de los museos. BRINDIS es una acción con la que se pretendía pensar en positivo por el reconocimiento de las mujeres en el sistema del arte brindando por la igualdad y la representatividad equilibrada en los museos y centros culturales del País Vasco. La acción consistió en recorrer la ciudad de Vitoria-Gasteiz situándonos frente a los espacios públicos, frente a los espacios más representativos del sistema del arte y en realizar brindis lanzando frases por el cumplimiento de las leyes de igualdad.

Recorrimos los siguientes equipamientos artísticos y culturales de la ciudad de Vitoria: el Museo Artium, el Centro Cultural Montehermoso, la Plaza de la Virgen Blanca y la Sala Amárica.

Nuevamente la Plataforma pedía a las instituciones y órganos competentes tomar medidas para el cumplimiento de las siguientes leyes de igualdad en las artes:

- Ley Orgánica 3/2007 para la igualdad efectiva de hombres y mujeres.

- vi Plan de Igualdad de Emakunde/Instituto Vasco de la Mujer.

- III Plan Foral para la Igualdad de hombres y mujeres en Álava.

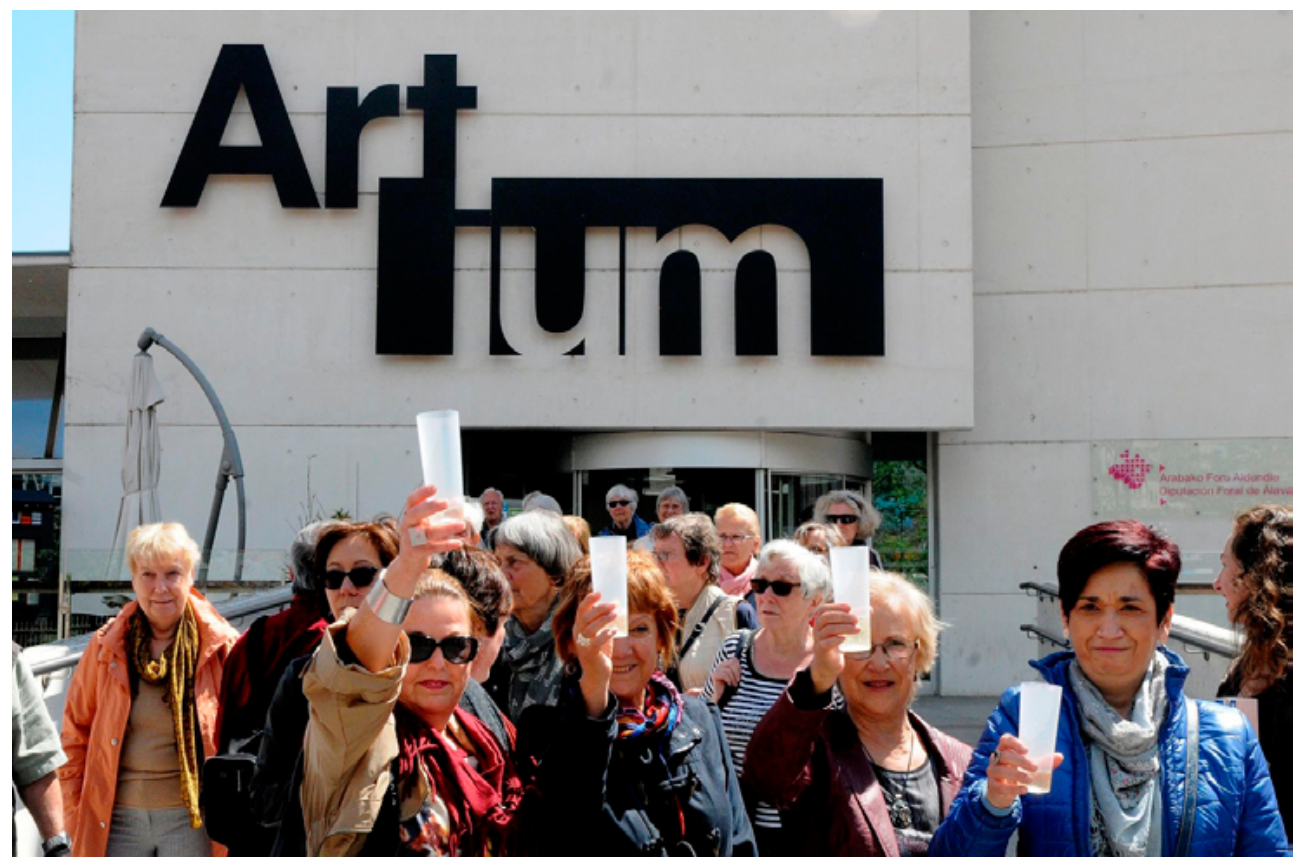

Figura 5. Acción «BRINDIS», Vitoria-Gasteiz, 17 de mayo de 2014. Fotografía: Elena Solatxi. 


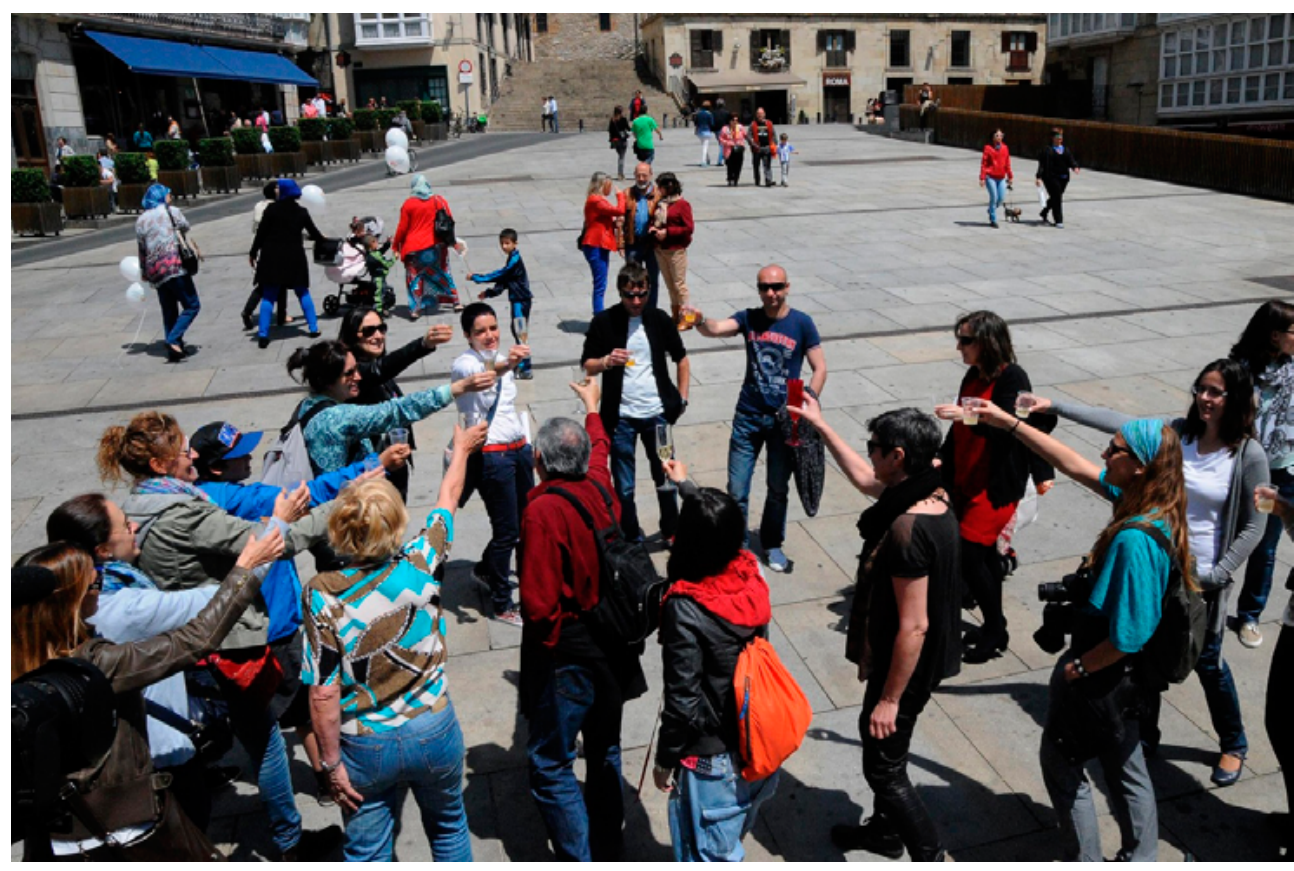

Figura 6. Acción «BRINDIS», Vitoria-Gasteiz, 17 de mayo de 2014. Fotografía: Elena Solatxi.

\section{Acción «TÚ NO»}

La acción $T U ́$ NO fue realizada frente a la entrada de la Facultad de Bellas Artes de la Universidad del País Vasco upv/EHu el 18 de febrero de 2015, fecha en que se cumplía el $10^{\circ}$ aniversario de la Ley 4/2005 del 18 de febrero para la Igualdad de Hombres y Mujeres, por lo que la Plataforma A ofreció también una sesión informativa para el alumnado.

La acción incidía en los mecanismos de inclusión y exclusión de género. El término gatekeeper, ${ }^{11}$ garante de calidad o autoridad selectiva, nos sirve para explicar la esencia de esta acción que consistió en utilizar la puerta de acceso al edificio dejando pasar o no pasar al interior en función del género pero sin explicitar que era por esa razón, y en caso de que alguien adujera este motivo, negarlo. La acción intentaba evidenciar así los mecanismos sublimi-

11. Gatekeeper, del inglés «el que cuida la puerta», es un guardián, un ser humano que controla el acceso a algo, por ejemplo, el acceso a la entrada de la ciudad. En el siglo xx el término empezó a usarse en sentido metafórico, en referencia a las personas que deciden si un determinado mensaje será distribuido por un medio de comunicación. Traducido de la definición inglesa en Wikipedia https://en.wikipedia.org/wiki/Gatekeeper (accedido el 28 de octubre de 2015). 
nales de discriminación de género. Se trataba de una acción camuflada por lo que no fue anunciada como acción artística.

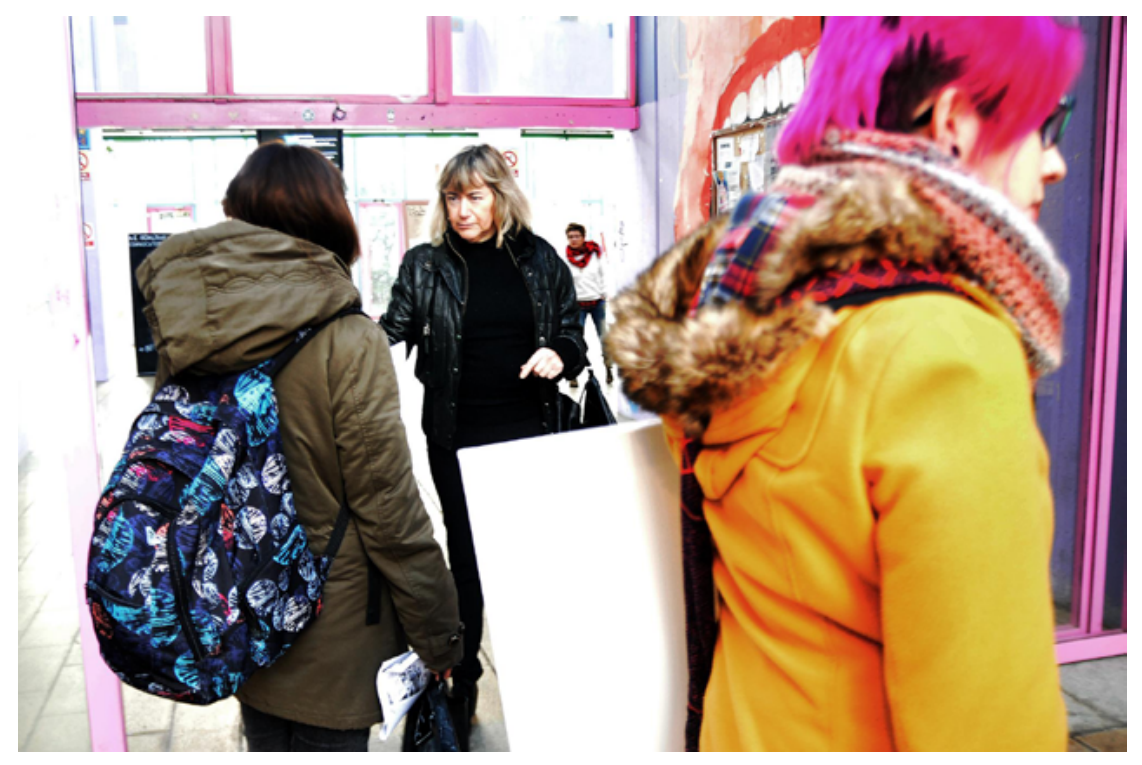

Figura 7. Acción «TÚ NO», Leioa, 18 de febrero de 2015. Fotografía: Elena Solatxi.

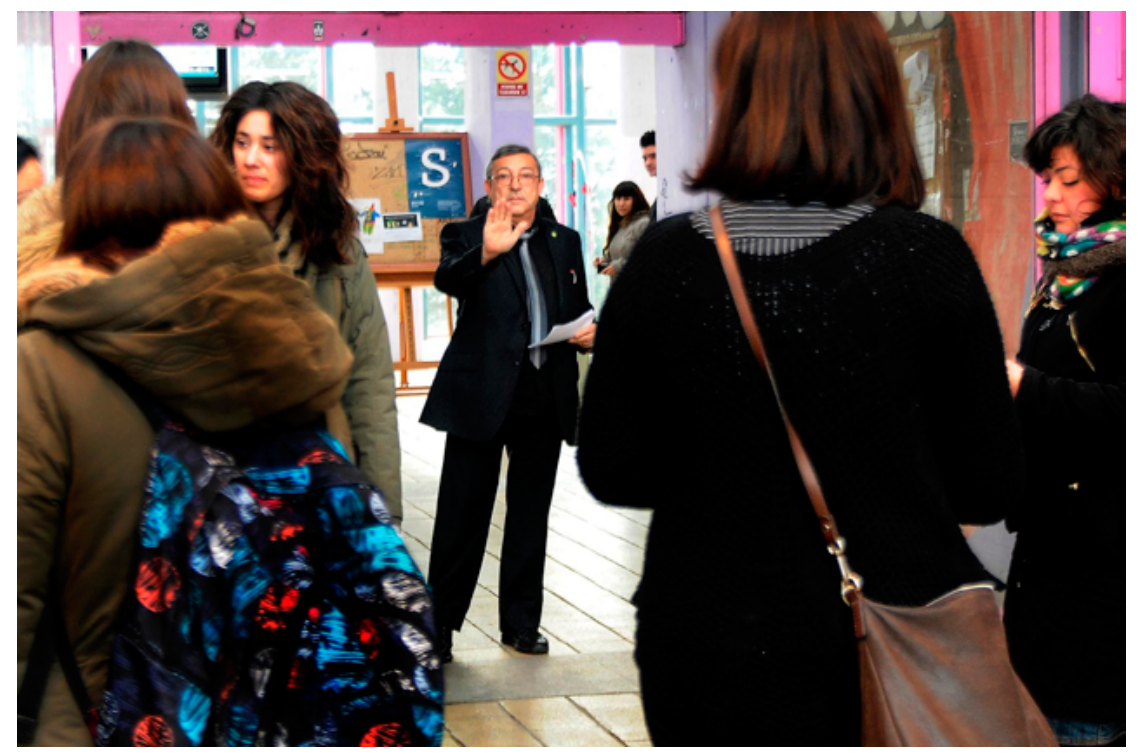

Figura 8. Acción «TÚ NO», Leioa, 18 de febrero de 2015. Fotografía: Elena Solatxi. 


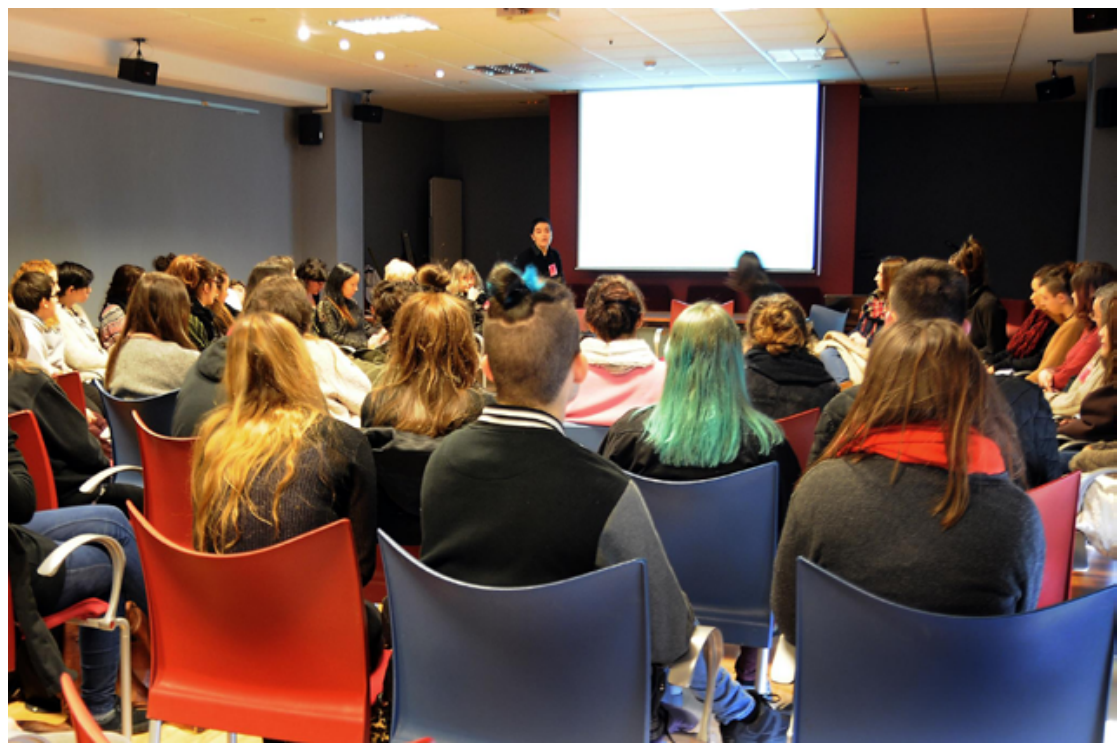

Figura 9. Sesión informativa de la Plataforma A en la Facultad de Bellas Artes de la Universidad del País Vasco UPV/EHU, tras la acción «TÚ NO», Leioa, 18 de febrero de 2015. Fotografía: Elena Solatxi.

En el material para la preparación de la acción TÚ NO, la artista Saioa Olmo explica el contexto para la acción:

Se supone que vivimos en una situación de igualdad de género. A nivel de discurso, parece existir el consenso (al menos en los países occidentales): mujeres y hombres deberíamos tener igualdad de derechos. Sin embargo, cuando miramos a nuestro alrededor y prestamos atención a las estadísticas, nos damos cuenta de que en la práctica, la situación dista de ser igualitaria y que hasta el momento, hay maneras tácitas, incluso inconscientes de discriminación en función del género y que como consecuencia, las mujeres tienen más dificultades para llegar a situaciones de poder, tienen menores salarios y ostentan más responsabilidades en la esfera reproductiva (la cual tiene menos valor social que la esfera productiva) y en general sufren modos subliminales de exclusión y de discriminación negativa debido al sistema heteropatriarcal imperante en la gran mayoría de culturas.

«Perdona pero tú... no puedes / no eres suficiente / no estás legitimada / no tienes credibilidad / no estás preparada para esto / no estás empoderada / no eres convincente / no te lo crees lo suficiente / no eres la persona adecuada / no sabes de esto / no eres de los nuestros / en lo que eres experta no tiene valor aquí / no eres competitiva... en definitiva, tú no.»

[...] Existe una incómoda construcción de género tanto para hombres como para mujeres, ya que conduce tanto a unas como a otros a ciertos 
patrones comportamentales y aspiracionales. Sin embargo, haciendo balance, pareciera que en este reparto, las mujeres tuvieran más las de perder. ${ }^{12}$

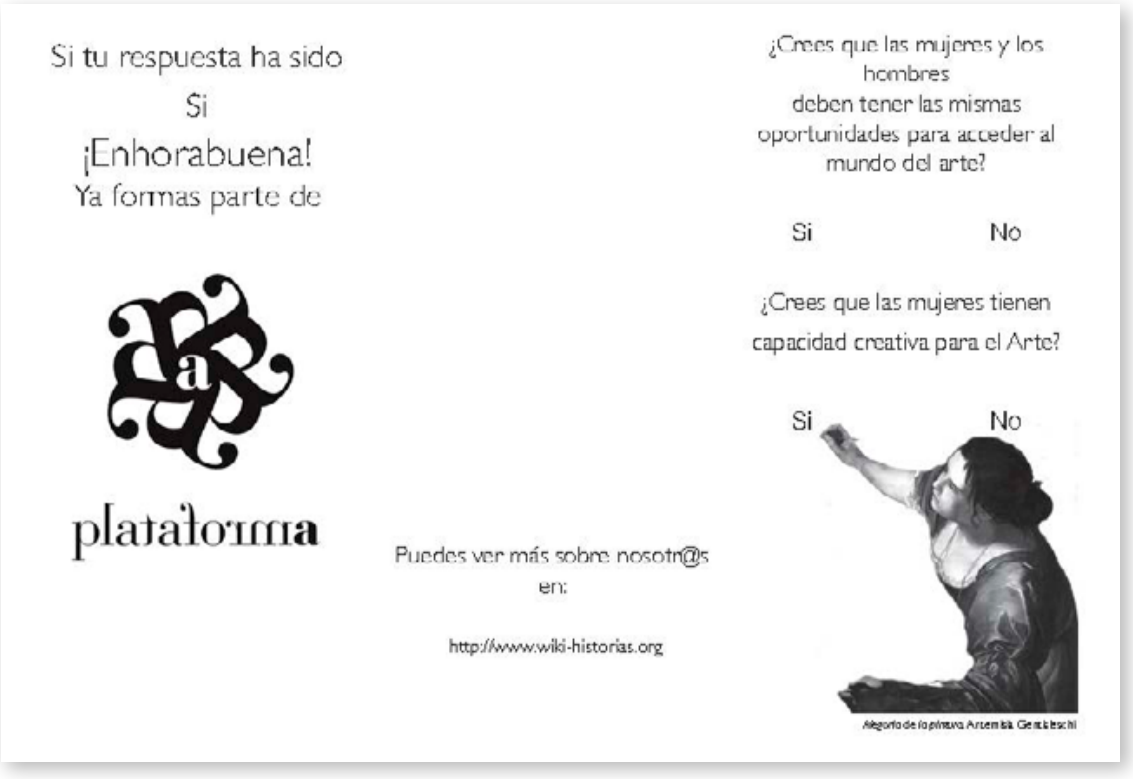

Figura 10. Tríptico para doblar utilizado en la sesión informativa en la Facultad de Bellas Artes de la Universidad del País Vasco, Leioa, 18 de febrero de 2015. Diseño: Raquel Asensi.

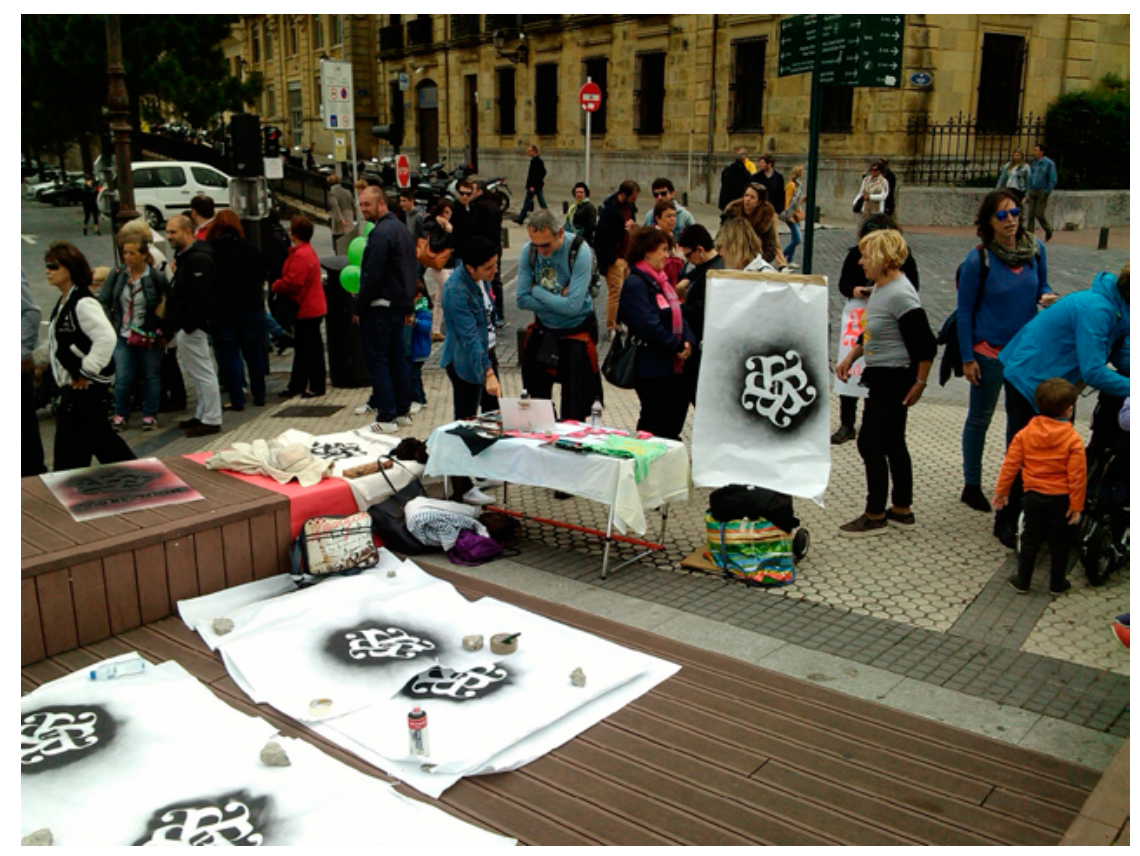

Figura 11. Sesión informativa «ENTÉRATE» realizada en San Sebastián el 18 de mayo de 2015. Fotografía: Txaro Arrazola.

12. Material propiedad de Plataforma A, documento preparativo de la acción «Brindis» desarrollado por Saioa Olmo. Ver www.wiki-historias.org (accedido el 18 de abril de 2016). 


\section{Las asambleas: encuentros o topaketak}

A lo largo del recorrido de la plataforma los encuentros han sido la herramienta de trabajo para llegar a acuerdos y crear todas las acciones llevadas a cabo. Hasta el momento hemos celebrado una media de tres encuentros (o asambleas) por año, en total 14 encuentros. Desde el primero el 24 de enero de 2012 en San Sebastián hasta el más reciente realizado el 23 de marzo de 2015 en Bilbao (fig. 22), todos ellos han sido asambleas abiertas en las que se han generado comisiones de trabajo específicas para la realización de las tareas acordadas. A través de las conclusiones y las actas de cada encuentro es posible hacer un seguimiento del devenir del colectivo.

Al primer encuentro, realizado en enero de 2012 en San Sebastián, se hizo un repaso de la Ley de Igualdad, asisten la Consejera de Cultura Blanca Urgell y la técnica de igualdad, Sonia González, ambas del Gobierno Vasco, y se comprometen a traer sus informes de participación para el próximo encuentro.

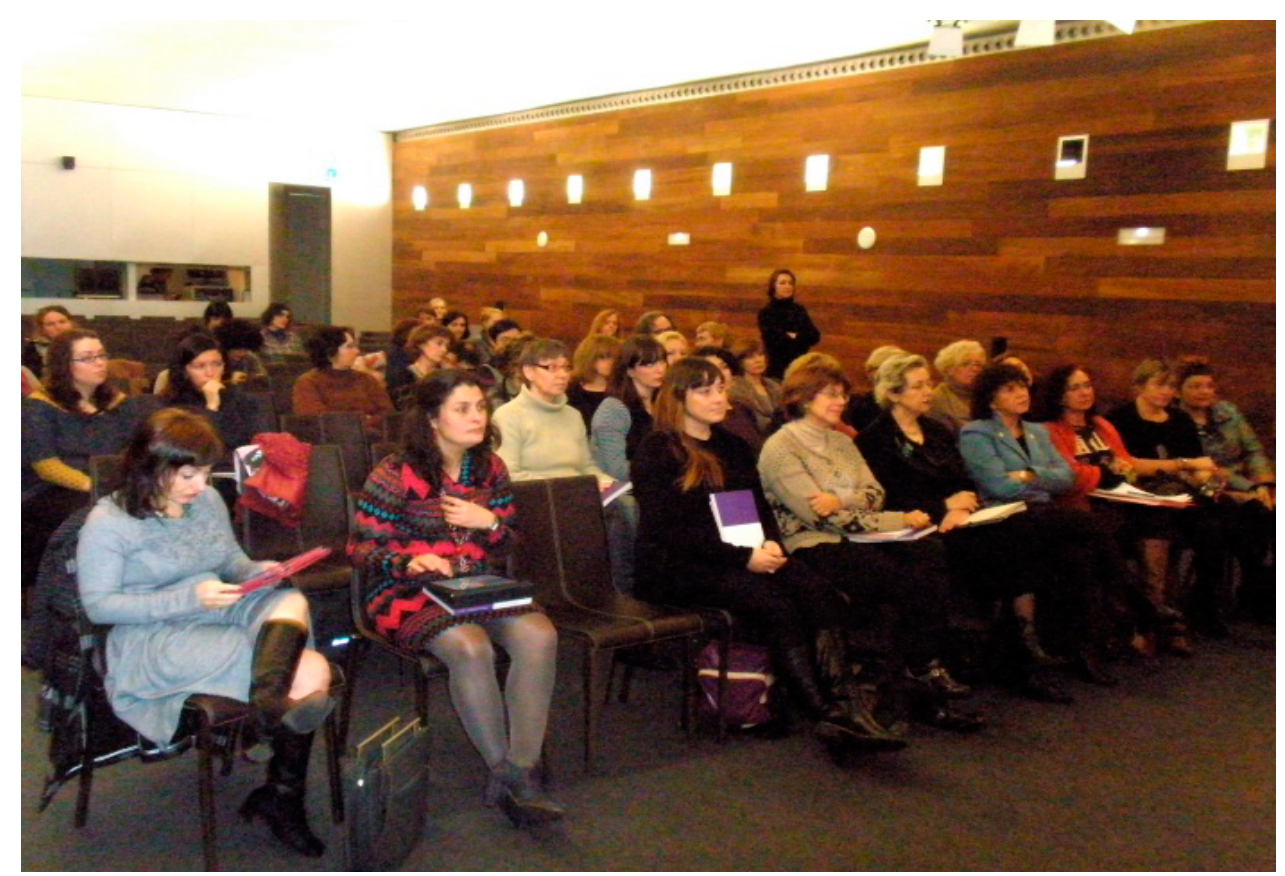

Figura 12. Primer encuentro de Plataforma A. Museo San Telmo, San Sebastián, 24/01/2012. Fotografía: Plataforma A. 


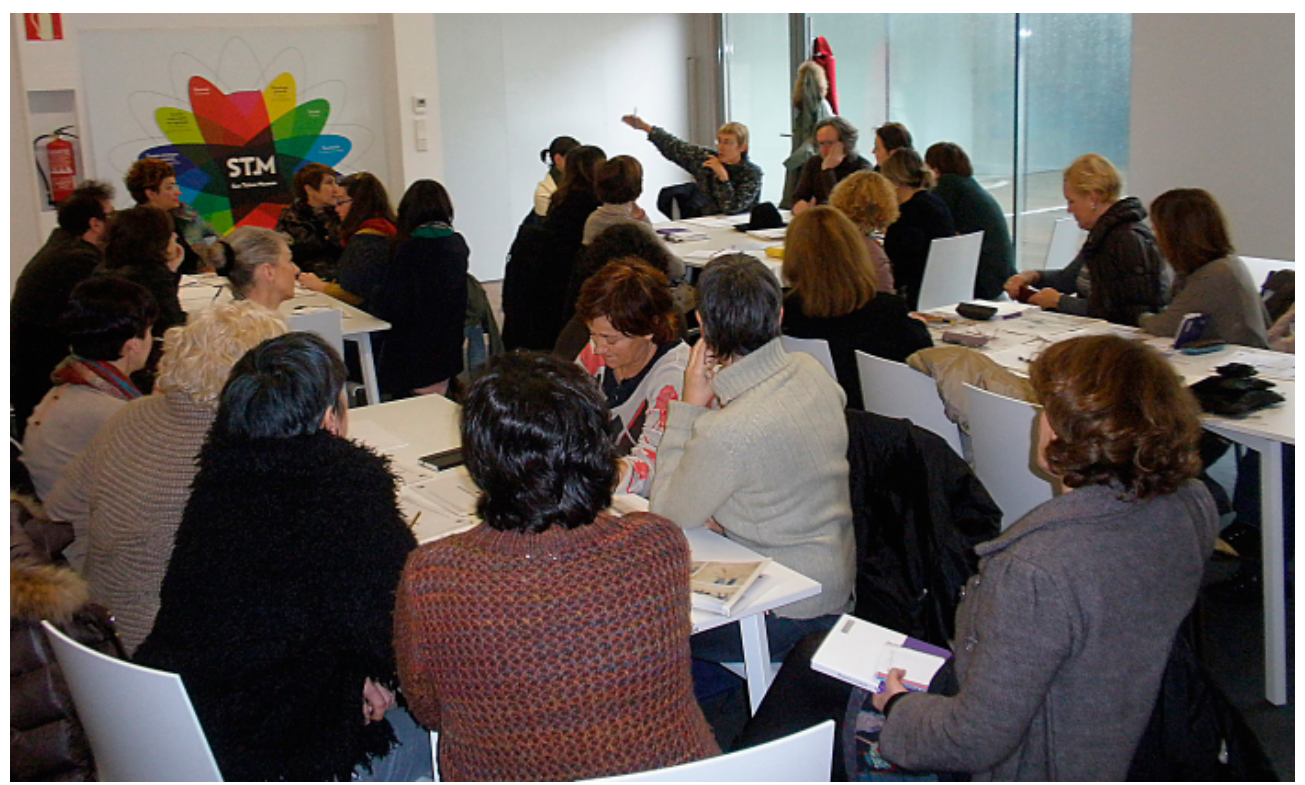

Figura 13. Primer encuentro de Plataforma A. Museo San Telmo, San Sebastián, 24/01/2012. Fotografía: Ma José Aranzasti.

En el segundo encuentro la plataforma se plantea dejar de estudiar el problema sociológicamente y actuar. El primer paso que se acuerda es hacer presión sobre las administraciones públicas, redactando un documento «manifiesto» para la aplicación de la ley en el que adoptamos dos líneas de acción:

- Agentes públicos (Departamento de Cultura, de Igualdad, Diputaciones, Defensor del Pueblo, Ayuntamientos, Emakunde, Concejalías, Museos, etc.)

- Medios de comunicación, para hacer visible el malestar que existe y extenderlo a la sociedad.

Como tercer punto, para desarrollar más adelante, se acuerda la necesidad de crear una comisión de seguimiento de la ley, comisión de expertos, formando parte de ella.

En la plataforma A nace la consciencia de que somos un motor que ha de poner en marcha el mecanismo de actuación, para ello se decide redactar una carta dirigida al lehendakari y consensuarla entre todas antes de enviarla al Gobierno vasco y a otros organismos, incluida la prensa. 


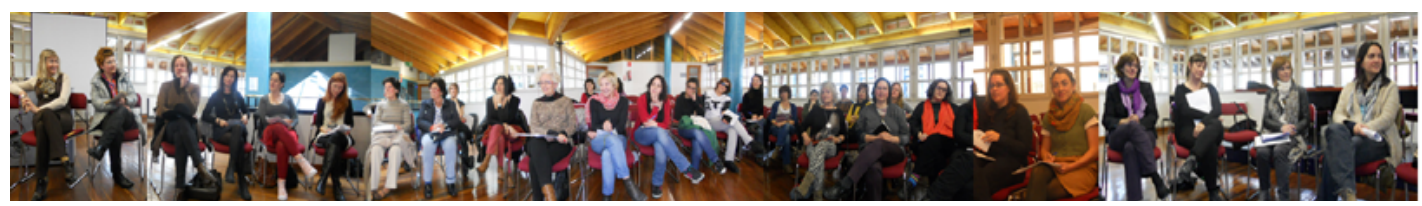

Figura 14. Segundo encuentro de Plataforma A, La Bolsa, Bilbao (21/04/2012). Fotografía: Pilar Soberón.

En el tercer encuentro realizado en Vitoria-Gasteiz en septiembre de 2012, se considera crear una recogida de firmas en Change.org y se decide crear una imagen corporativa de Plataforma A, como trabajo real de los/las estudiantes de la Escuela de Diseño, adaptada a medios online y offline.

- De cada encuentro han de salir una o varias personas que tomen el relevo.

- Pensando en el próximo cambio de gobierno se propone enviar la carta si es necesario al nuevo lehendakari. Además, se ve aconsejable enviarla a partidos políticos, universidad, museos, galerías, Defensor del Pueblo y Emakunde.

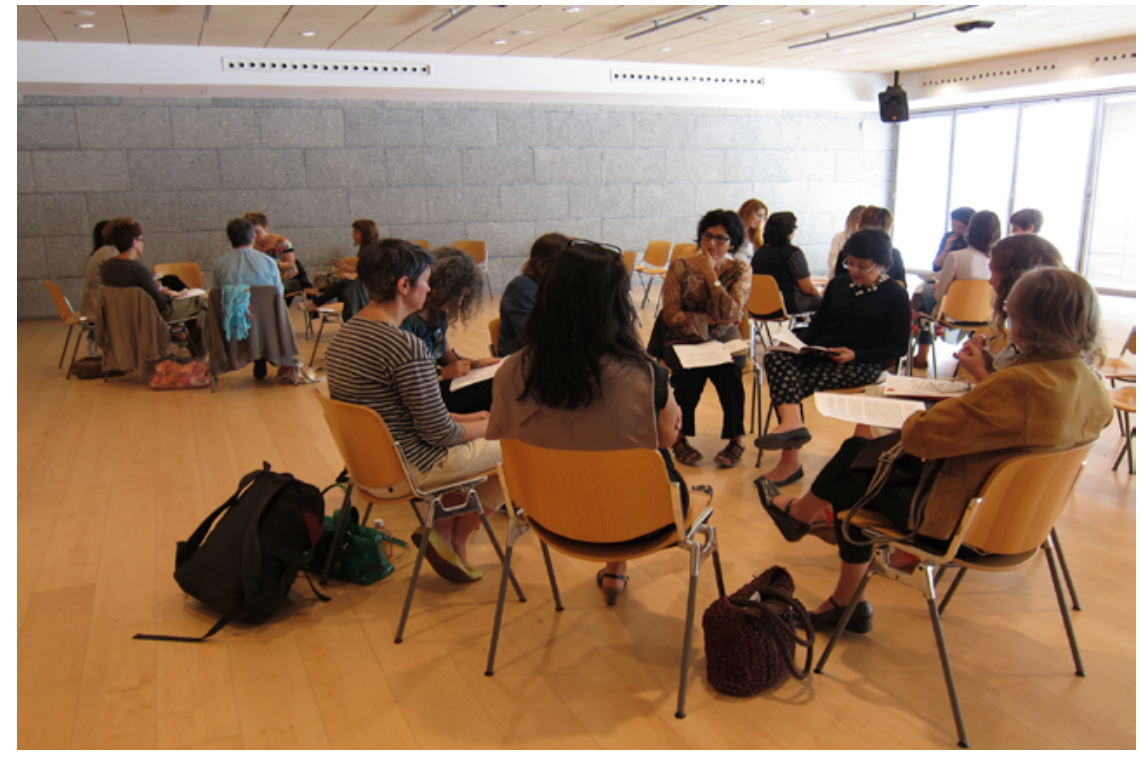

Figura 15. Tercer encuentro de Plataforma A, Artium, Vitoria-Gasteiz (15/09/2012). Fotografia: Plataforma A.

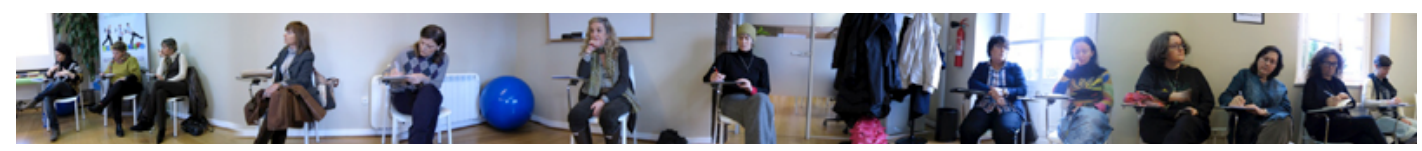

Figura 16. Taller para Plataforma A en Fundación Trocóniz, 29/11/2012, Portugalete (Vizcaya). Fotografía: Pilar Soberón. 


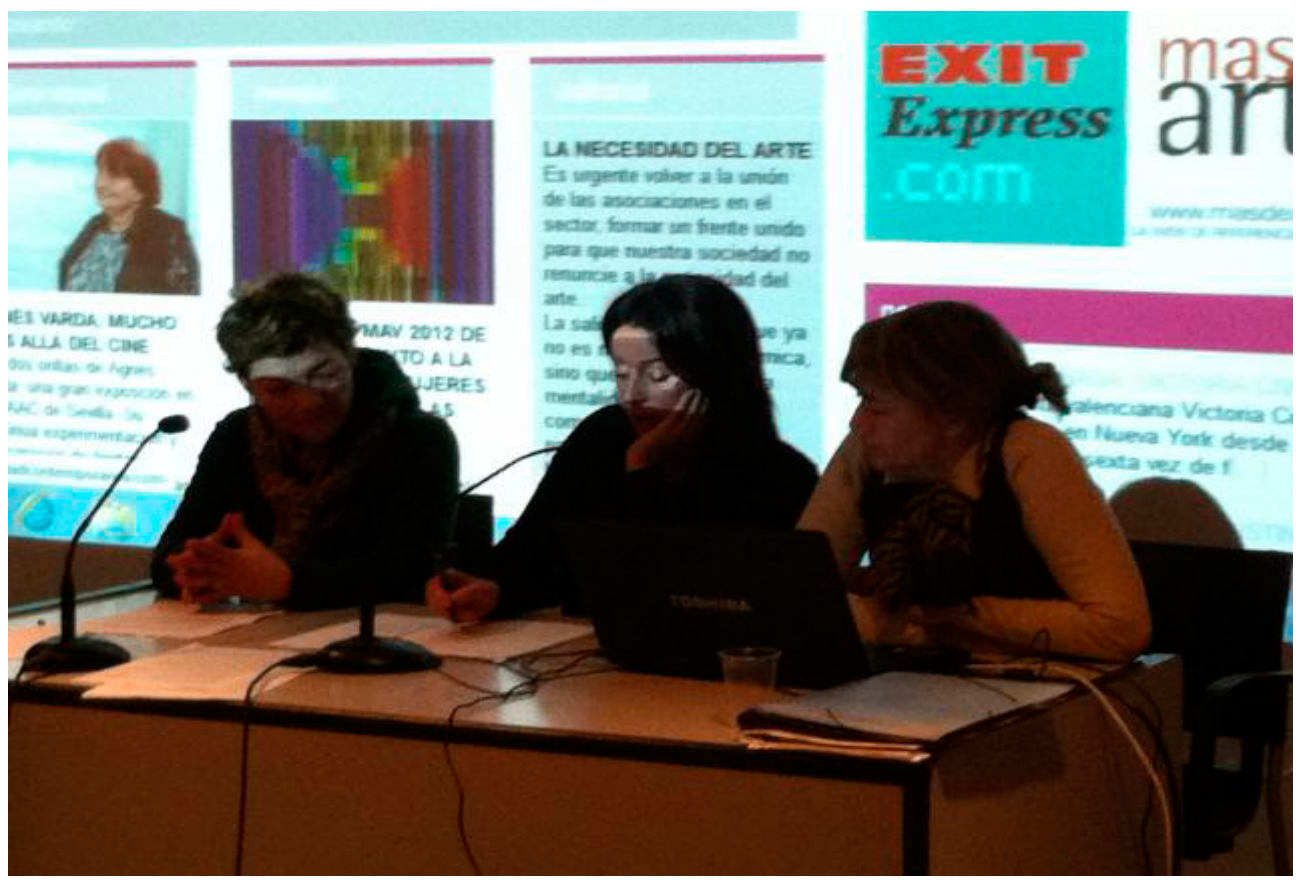

Figura 17. Conferencia de Pltaforma A en Feministaldia, Arteleku, San Sebastián (15/12/2012). Fotografía: Plataforma A.

En el cuarto encuentro se repartieron tareas para la siguiente sesión señalando la importancia de que estas tareas fueran rotando:

- Equipo de comunicación.

- Personas dispuestas a hablar con los medios.

- Persona encarga del mailing.

- Coordinación del siguiente encuentro.

- Recopilación de los resultados del taller de escritura.

- Dar acceso a las propuestas de identidad visual discutidas en la sesión.

Aquí se adjuntan las definiciones elaboradas en el taller y abajo se adjunta el material de trabajo que muestra el proceso colaborativo: 
Definiciones de Plataforma A desarrolladas en el cuarto encuentro: ${ }^{13}$

PLATAFORMA A somos una trenza que relaciona diferentes vías de trabajo y de investigación, desde el grupo y la unidad buscando presencia y visibilidad en los diferentes ámbitos del arte y la cultura.

PLATAFORMA A es un grupo de personas que pretende generar un efecto dominó de igualdad de oportunidades en el contexto artístico. Un esfuerzo grupal que se basa en un reconocimiento horizontal. Basta ya de asumir políticas culturales aparentemente neutras. Queremos que se implementen medidas para que hombras, mujeros u otros seres con género por definir tengamos las mismas oportunidades en espacios expositivos, difusión, mercado y espacios de decisión en el arte.

PLATAFORMA A apuesta por que el reconocimiento de las mujeres en los espacios de poder es la solución para una interacción equitativa.

PLATAFORMA A ha sido creada para la construcción del espacio que corresponde a la mujer en el arte; con nuestra presencia y tejiendo las diferencias trabajamos para abrir puertas hacia el cambio.

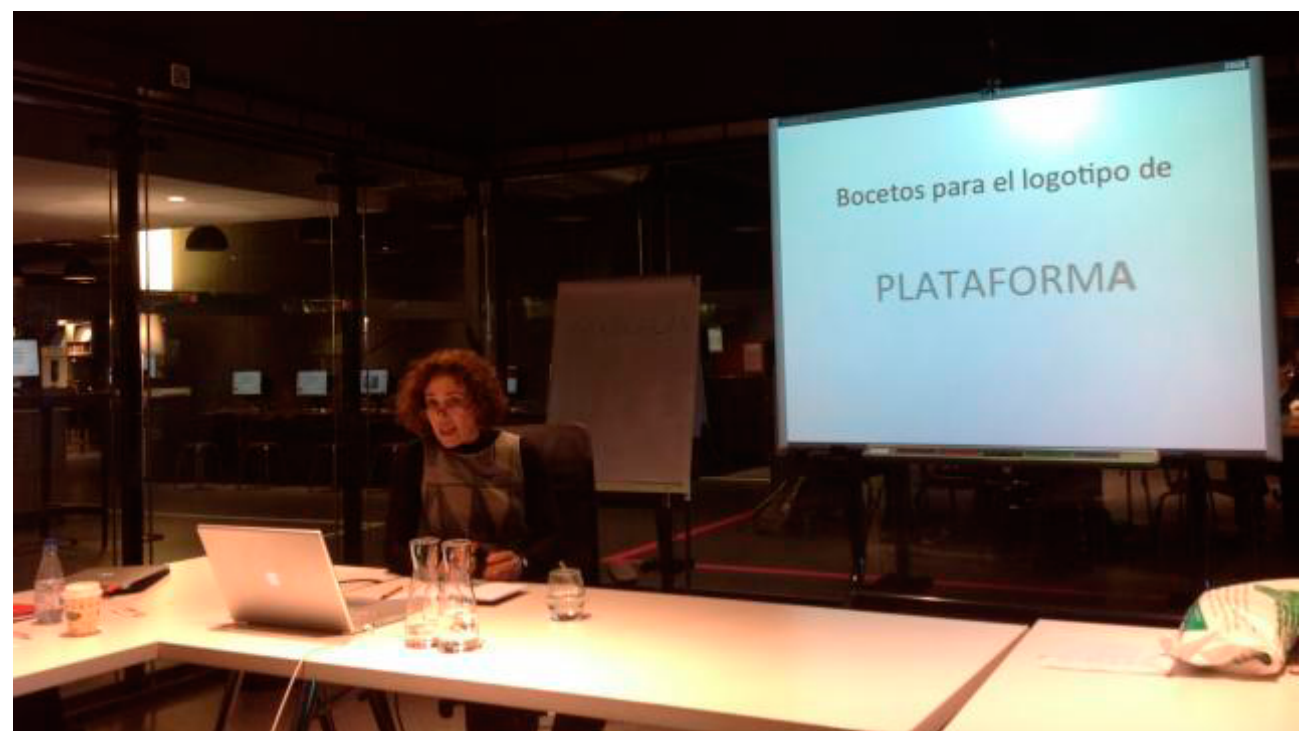

Figura 18. Mònica Serentil presentando las propuestas para logotipo en el cuarto encuentro de Plataforma A celebrado en Alhóndiga Bilbao, Bilbao (26/01/2013).

Fotografía: Plataforma A.

13. Definiciones de la plataforma A extraídas del material de archivo del taller de escritura colectiva realizado en el cuarto encuentro con la ayuda de Marisa Gutiérrez. 


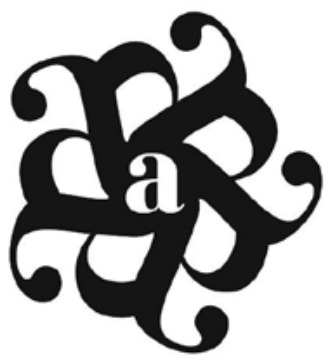

platatorma

Figura 19. Logotipo de Plataforma A, diseñado por iniciativa de una de las miembros de Plataforma A con la colaboración de la Escuela de Arte y Superior de Diseño de Vitoria-Gasteiz. Diseño: Ion Romero.

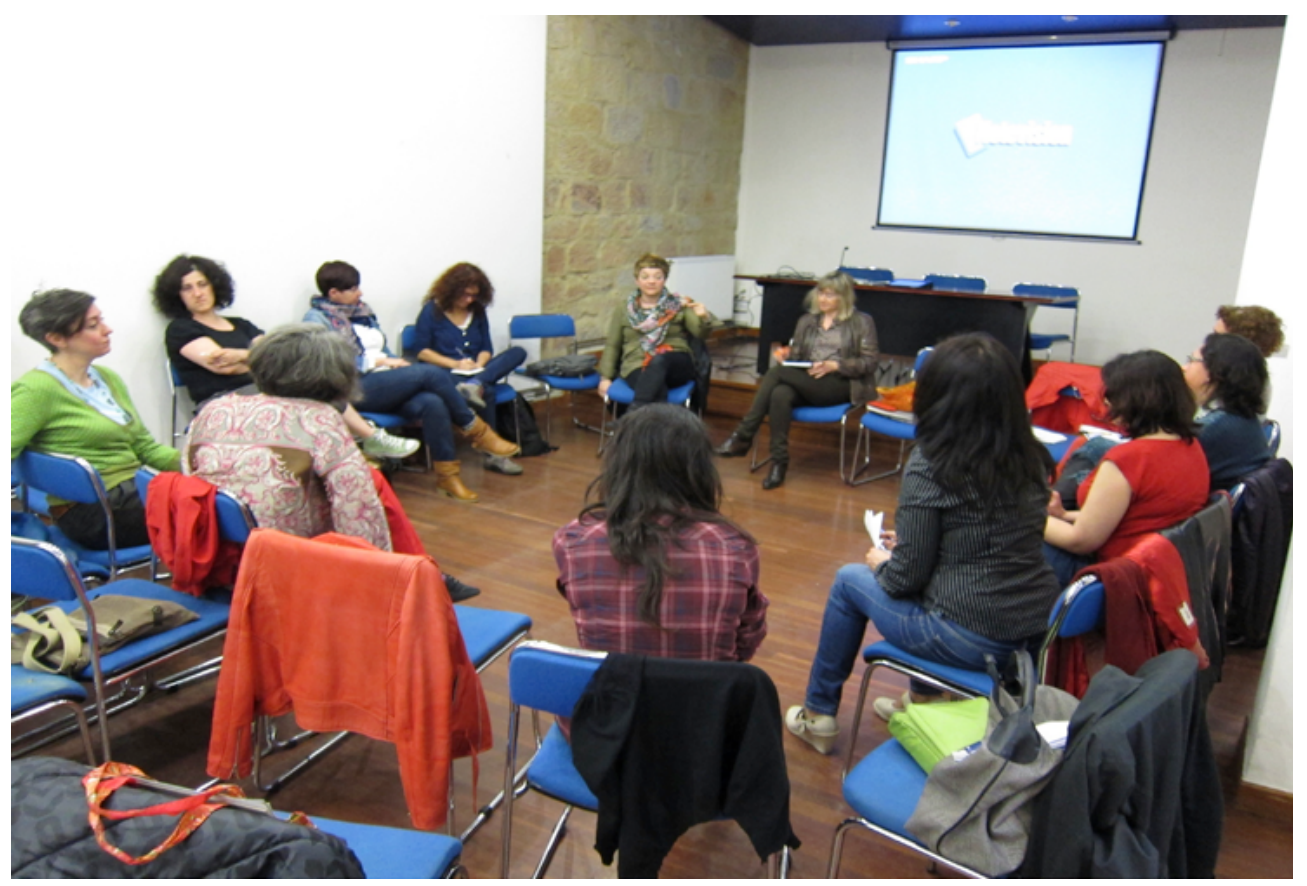

Figura 20. Quinto encuentro de Plataforma A, Distrito de la Bolsa, Bilbao (11/05/2013). Fotografia: Plataforma A.

En el sexto encuentro, participamos a toda la Plataforma A la noticia de que el Gobierno vasco por medio del defensor del pueblo y Emakunde (Instituto Vasco de la Mujer) nos ha pedido que participemos en la redacción del VI Plan de Igualdad del Gobierno Vasco (2014-2018). 
Se decide utilizar google groups para comunicarnos en los tiempos muertos entre encuentros. ${ }^{14}$

En el octavo encuentro ideamos la acción «BRINDIS», una acción de carácter positivo para reivindicar que se cumpla la Ley de Igualdad en las Artes.

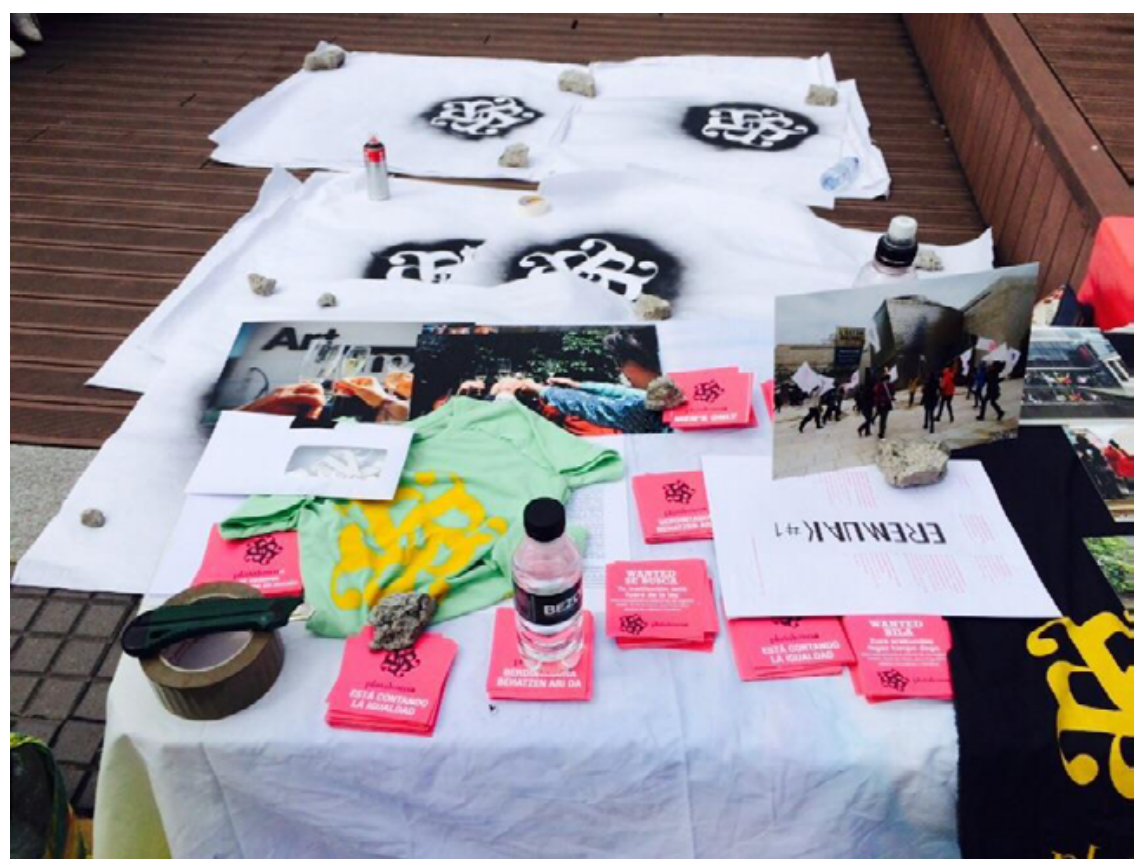

Figura 21. Presentación y taller de stencils en Donostia/San Sebastián, 17 de mayo 2015. Fotografia: Txaro Arrazola.

\title{
Reflexión final. El caso del Centro Cultural Montehermoso Kulturunea
}

\author{
Elegir el sexo como criterio curatorial \\ es dinamitar la mística del arte.
}

\section{Lourdes Méndez}

Pese a las reticencias mostradas por algunos de los responsables de los museos y administraciones públicas al respecto de la posibilidad real de programar con conciencia igualitaria, tenemos un ejemplo cercano pionero en la

14. Email colectivo de Plataforma A: plataforma a@googlegroups.com. 
aplicación de las cuotas de sexo en el arte y la cultura, conocido en el ámbito de la plataforma como el «Modelo Monthermoso». Entre los años 2007 y 2011 el Centro Cultural Montehermoso Kulturunea de Vitoria-Gasteiz, bajo la dirección de Xabier Arakistain, desarrolló una programación de arte contemporáneo que respetaba las cuotas de igualdad y ponía de manifiesto que se puede hacer una política cultural inclusiva y al mismo tiempo ganar en calidad e interés discursivo incorporando la igualdad como factor transversal en las programaciones de exposiciones, conferencias, comisariado, etc.

Una vez desaparecido el modelo, los porcentajes de exposiciones de artistas mujeres bajaron a los índices habituales en los que la participación de mujeres no supera el 15 o el $20 \%$, por lo tanto, es evidente que la aplicación de las cuotas de sexo es una medida práctica y hoy por hoy necesaria para que las artistas sean reconocidas en todas las instancias de la institución arte.

La plataforma no tiene socias, ni siquiera es una asociación y creemos que ésa es su fuerza, somos un fantasma que se cierne sobre las instituciones, no se sabe cuántas ni quiénes somos realmente, somos todas. No contamos con ningún presupuesto, nos movemos poniendo dinero de nuestro bolsillo y si hay suerte tiramos de lo que sacamos por dar alguna sesión informativa o conferencia. Quizá es pronto para valorar lo que hemos conseguido, quizá sean logros pequeños aunque esperamos que abran camino. Los cambios más inmediatos están teniendo lugar en las sesiones informativas donde hacemos saber los porcentajes que dan cuenta de la tremenda desproporción entre la cantidad de mujeres con formación en arte y su escasa presencia en el circuito expositivo profesional. Aunque parezca mentira, hay muchísima gente que ni lo sabe ni se da cuenta de ello y les abrimos los ojos, que ya es buen comienzo.

¿Por qué es importante que estemos? El objetivo es erradicar la desigualdad en el campo del arte contemporáneo. Necesitamos nuevos referentes para un cambio de valores que acepte la diversidad. Las mujeres deben estar presentes porque van a dejar distintas imágenes y maneras de pensar a la siguiente generación. Necesitamos modelos de referencia capaces de acabar con la inercia del actual sistema de exclusiones generado por una autoridad patriarcal que margina o convierte en tendencia ciertas prácticas para perpetuar su propia jerarquía. 


\section{Referencias bibliográficas}

Amorós, C. (1991 [1985]): «Hacia una crítica de la razón patriarcal», Barcelona, Anthropos.

Arakistian, X. (ed.) (2007): Kiss Kiss Bang Bang. 45 Años de arte y feminis$m o$, Museo de Bellas Artes de Bilbao, Bilbao.

— MÉndez, L. (2014): Revista ERRATA\# 12, DESOBEDIENCIAS SEXUALES, «El sexo como categoría curatorial. Una apuesta politica» [en línea] $<$ http:// revistaerrata.com/ediciones/errata-12-desobediencias-sexuales/ el-sexo-como-categoria-curatorial-una-apuesta-politica>.

Barcenilla, H. (2011): «Million Dollar Baby. Sobre adquisiciones artísticas y género. Un caso en Euskadi», $A * D E S K$ Magazine, 86 [en línea] $<$ http://www.a-desk.org $>$.

De Beauvoir, S. (1949): Le deuxième sexe, TI, Gallimard, Paris.

Lippard, L. R. (1976): From the Center. Feminist essays on women's art, Toronto, Fitzhenry \& Whiteside Limited.

Martínez-Collado, A. (2011): «Releer/Reescribir la historia, los conceptos, las imágenes. ¿Heroínas, hoy?», en Agencia feminista y empowerment en artes visuales/ Feminist Agency and empowerment in Visual Arts, Madrid, MuseoThyssen-Bornesmiza, 139-152. [en línea] $<$ http://www.culturagalega.org/album/docs/198_amp_016.pdf $>$.

MÉNDEz, L. (2005): «Una connivencia implícita: "perspectiva de género", "empoderamiento" y feminismo institucional», en ANDRIEU, R. y Mozo, C. (coords.) Antropología feminista y/o del género. Legitimidad, poder y usos políticos, Sevilla, El Monte, FAAEE, AAA, pp. 203-226.

- (2011) «Ellos, artistas a secas; ellas, 'mujeres artistas'; que no es lo mismo», en Agencia feminista y empowerment en artes visuales/Feminist Agency and empowerment in Visual Arts, Museo Thyssen-Bornesmiza, Madrid, pp. 153-169.

— (2014) «Feminismos en movimiento en el Estado español: ¿re-ampliando el espacio de lo político?», Revista Andaluza de Antropología, 6, ISSN 2174-6796 [en línea] <http://www.revistaandaluzadeantropología.org>.

Nochlin, L. (1973 [1971]): «Why have there been no great women artist?», en Hess, Tн. B. y E. C. BaKer (eds.) Art and sexual politics, Macmillan, New York, pp. 1-43.

Pollock, G. (1994): «Histoire et politique: l'histoire de l'art peut-elle survivre au féminisme?» en Féminisme, art et histoire de l'art, (énsb-a), Paris, pp. 63-90. 
- (2008): «Producción Artística y Teoría Feminista del Arte: Nuevos Debates I», en Arakistain, X. y Méndez, L. (2008), Proyecto «Actas», Centro Cultural Montehermoso Kulturunea, Ayuntamiento de Vitoria-Gasteizko Udala.

Rodríguez-Escudero, P. y L. Méndez (eds.) (1987): Arte y Mujer, upv/ehu, Donostia-San Sebastián.

Vila Nuñez, F. (2007): «Guerrilla Girls», en Arakistain, X. (ed.) (2007), Kiss kiss Bang Bang. 45 Años de arte y feminismo, Museo de Bellas Artes de Bilbao, Bilbao, pp. 220-226. 
318

EXTRAMURS

kultur 